\title{
EXPERIMENTS FOR IFR FUEL CRITICALITY IN ZPPR-21
}

\author{
D. N. Olsen, P. J. Collins and S. G. Carpenter
}

Argonne National Laboratory - West

P. O. Box 2528

Idaho Falls, ID 83403-2528

\begin{abstract}
Paper submitted to:
ICNC '91 International Conference on Nuclear Criticality Safety

September 9-13, 1991

Oxford, United Kingdom
\end{abstract}

Work supported by the U.S. Department of Energy, Nuclear Energy Programs, under Contract W-31-109-Eng-38 The submitted manuscript has been authored
by a contractor of the U. S. Governmen:

under contract No. W-31-109ENG-38.

Actordingly, the U.S. Government retains a

nonexclusive, rovalty-tree license to publish

contribution, or allow others to do so, for

U. S. Government purposes. 


\section{DISCLAIMER}

This report was prepared as an account of work sponsored by an agency of the United States Government. Neither the United States Government nor any agency thereof, nor any of their employees, makes any warranty, express or implied, or assumes any legal liability or responsibility for the accuracy, completeness, or usefulness of any information, apparatus, product, or process disclosed, or represents that its use would not infringe privately owned rights. Reference herein to any specific commercial product, process, or service by trade name, trademark, manufacturer, or otherwise does not necessarily constitute or inply its endorsement, recommendation, or favoring by the United States Government or any agency thereof. The views and opinions of authors expressed herein do not necessarily state or reflect those of the United States Government or any agency thereof. 
EXPERIMENTS FOR IFR FUEL CRITICAIITY IN ZPPR-21

D. N. Olsen, P. J. Collins, and S. G. Carpenter

Argonne National Laboratory - West, Idaho Falls, Idaho, USA

ABSTRACT

A series of benchmark measurements was made in ZPPR-21 to validate criticality calculations for fuel operations in Argonne's Integral Fast Reactor. Six different mixtures of Pu/U/Zr fuel with a graphite reflector were built and criticality was determined by period measurements. The assemblies were isolated from room return problems by a lithium hydride shield. Analysis was done using a fully-detailed model with the VIM Monte Carlo code and ENDF/B-V.2 data. Sensitivity analysis was used to validate the measurements against other benchmark data. A simple Rz model was defined and used with the KENO code. Corrections to the RZ model were provided by the VIM calculations with low statistical uncertainty.

\section{INTRODUCTION}

Fuel processing operations for the Integral Fast Reactor (IFR) at Argonne-West require assurance of the safety of metallic fuel in different quantities and geometries that could arise in the crucible. [1] The fuel may contain different proportions of plutonium and uranium with zirconium. No experimental data existed to validate criticality calculations for fuel of this type although data are available for plutonium and uranium separately without zirconium.

A series of six critical cores was build in Argor...'s zero Power Physics Reactor (ZPPR) in 1990. The core size was kept constant, at 46 liters, and each core was adjusted to critical by varying the thickness of a graphite reflector. The core compositions were changed progressively from an all-plutonium fuel loading to an all-uranium fuel loading with zirconium kept constant. Critical masses ranged from $94 \mathrm{~kg}$ in the Pu core (ZPPR-21A) to 163 $\mathrm{kg}$ in the uranium core (ZPPR-21F). Fuel enrichments were in the range 0.43 to $0.56 \mathrm{w} / 0$ with zirconium fraction of about $0.12 \mathrm{w} / 0$. The assemblies were surrounded by natural-lithium hydride shield to provide a calculable boundary .

Calculations for ZPPR-21, with ENDF/B-V.2 data, were made in full detail using the Monte Carlo code VIM. [2] The input data were constructed automatically using a utility code which processes the ZPPR reactor database. A vast amount of input data is required for the complete description of the ZPPR assemblies. This must be constructed automatically to avoid human errors. At present, a processing code for ZPPR is available only for VIM although preliminary work has been done in conversion to the format required by the MCNP code.

A simple RZ geometry model has been defined for ZPPR-21 which uses homogenized region compositions. Corrections to the models for geometry and heterogeneity have been provided from calculations with the vIM code. The corrections are given to a statistical accuracy of $0.17 \% \Delta \kappa$, or better, which is sufficient for many purposes. 
A detailed sensitivity analysis has been made for 2PPR-21. Results are shown :o be consistent with the benchmark cores; GODIVA, JEZEBEL and the FLATTOPS and with a range of critical experiments for the IFR and fast reactors in general. This work demonstrates the high quality of the data.

The validated method for criticality safety caiculations at ANL-W is use of the KENO-5a code and data. [3] This has been used with the Rz model and gecmetrical corrections to provide experimental data with which to justify safety analysis for the IFR fuel operations.

\section{THE EXPERIMENTS}

The 2PPR machine has a "split-halves" construction with a square thin steel mat ix with dimension $55 \mathrm{~mm} \times 55 \mathrm{~mm}$. Material platelets are loaded in steel drawers which are inserted in the matrix to form regions of a required composition. The core of ZPPR-21 was nominally cylindrical in shape with 40 $\mathrm{cm}$ height and about $19 \mathrm{~cm}$ effective radius. Six different plate-type cells were used in the core to vary the $D u / U$ composition in assemblies $21 \mathrm{~A}$ to $21 \mathrm{~F}$. The core size was kept constant and the fuel compositions were varied by changing the initial loading of Pu-U-Mo plates (ZPPR plutonium) and Pu plates to combinations of ${ }^{235} \mathrm{U}$ plates and steel plates. The six cell loadings in the core are illustrated in Figure 1. The principal mass loadings are given in Table 1.

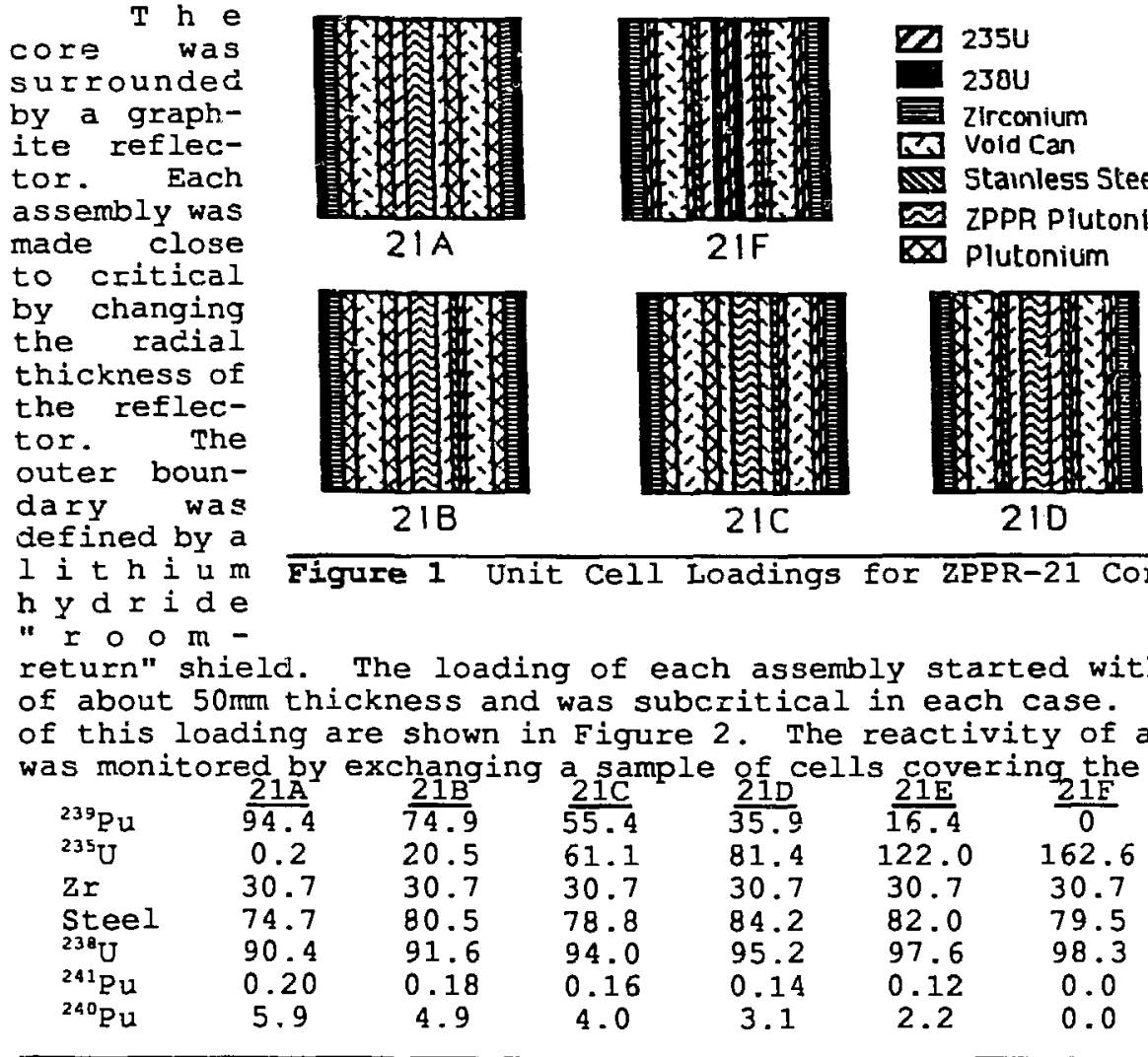

Table I Principal Mass Loadings in ZPPR-21 Cores, kg

a thin reflector $\mathrm{XY}$ and $\mathrm{RZ}$ sections given cell change core volume. Then the remainder of the cells were changed following the ZPPR rules for the approach to critical. Final adjustment was made by symmet rica I increases in $r$ e 1 e c t or thickness while monitoring the inverse contrates with a number of internal and external detectors. The final reactivity was established by period measurements, with the fueled safety rods fully inserted and boron control 
rods withdrawn, to establish a clean configuration. The uranium assembly, $21 F$, required a start-up source, which was withdrawn to monitor the final reactivity.
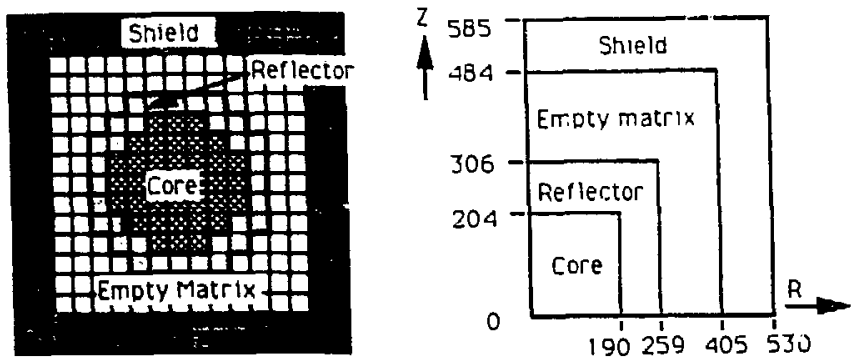

The reflector loadings for assemblies $21 \mathrm{~A}$ to $21 \mathrm{~F}$ are shown in Figure 3. Each core had the same shield, shown in Figure 2, and the core cells are shown in Eigure 1.

The excess reactivities in ZPPR-21 are given in Table II. The period measurements give reactivities in dollars which are converted to K-eff using the calculated values for B-eff shown.

Uncertainties in measured excess reactivity are small, less than $0.0025 \$$ and uncertainties in B-eff are about $4 \%$. An assessment of uncertainties in ZPPR k-eff is given by McKnight. [4] In ZPPR-21, the total uncertainty is dominated by knowledge of the fuel mass and the interface gap in the ZPER machine. These two components are each strongly correlated between assemblies $A$ to $F$. Total uncertainties in $\mathrm{K}$ eff vary from $0.12 \% \Delta \mathrm{k}$ in $21 \mathrm{~A}$ to $0.21 \% \Delta \mathrm{k}$ in $21 \mathrm{~F}$.

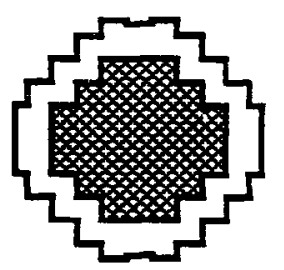

$21 \mathrm{~A}$

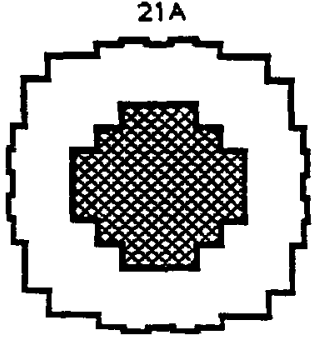

210

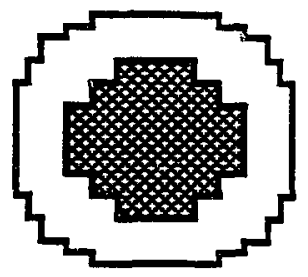

218

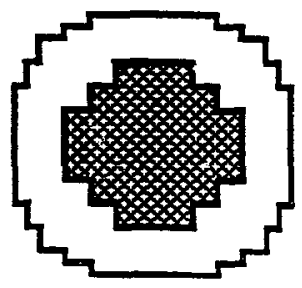

2 IE

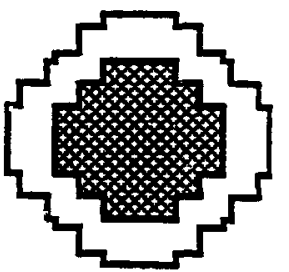

210

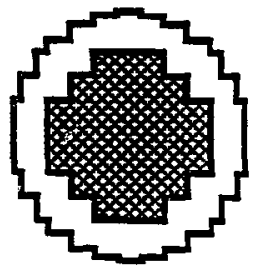

$21 F$

Figure 3 Reflector Loadings in Assemblies 21A to 21F

\begin{tabular}{|c|c|c|c|c|}
\hline Assembly & $\begin{array}{c}\text { Measured } \\
\text { Reactivity, } \\
\end{array}$ & B-effective, $\frac{q}{8}$ & k-effective & $\begin{array}{c}\text { Uncertainty, } \\
\text { 官 } \Delta \mathrm{k}\end{array}$ \\
\hline$\overline{\text { ZPPR-21A }}$ & 8.2 & 0.283 & 1.00023 & 0.124 \\
\hline ZPPR-21B & 2.7 & 0.352 & 1.00009 & 0.125 \\
\hline ZPPR-21C & -15.5 & 0.465 & 0.99928 & 0.138 \\
\hline ZPPR-21D & 24.7 & 0.547 & 1.00135 & 0.161 \\
\hline ZPPR-21E & 14.2 & 0.647 & 1.00092 & 0.183 \\
\hline ZPPR-21F & 7.8 & 0.724 & 1.00056 & 0.207 \\
\hline
\end{tabular}

Table II Experimental k-effs and Uncertainties in ZPPR-21 


\section{CALCULATIONS WITH THE VIM MONTE CARLO CODE}

VIM [2] is a continuous-energy Monte Carlo code. A plate-lattice geometry option is ideally suited for representation of ZPPR and is efficient in operation. Models for zPPR-21 were set up automatically from the reactor data base with a processing code. The assemblies were modelled in great detail including representation of the matrix, drawers, plate clads and airgaps. The models had, typically, 2000 zones, 17 unit cells and 90 compositions. The VIM calculations were run for 500 thousand histories, in batches of 10 thousand. The first five batches were discarded in the tallies to converge the starting source in the fuel. Results with ENDF/B-V.2 data are given in Table III. The result chosen for comparison with experiment is that for the combined analogue and track length estimators, including correlations, which has the lowest variance of any pair. Final uncertainties were close to $0.1 \%$ in any case.

The ENDF/BV.2 data give good predictions for ZPPR-21 with a systematic variation in the error of $+0.44 \% \pm 0.16 \%$, with plutonium fuel, to $-0.21 \%$ $\pm 0.24 \%$ with uranium fueI. A plot of the results as a function of ${ }^{235} \mathrm{U}$

fuel to total $\mathrm{Pu}+\mathrm{U}$ is given in Eigure 4 .

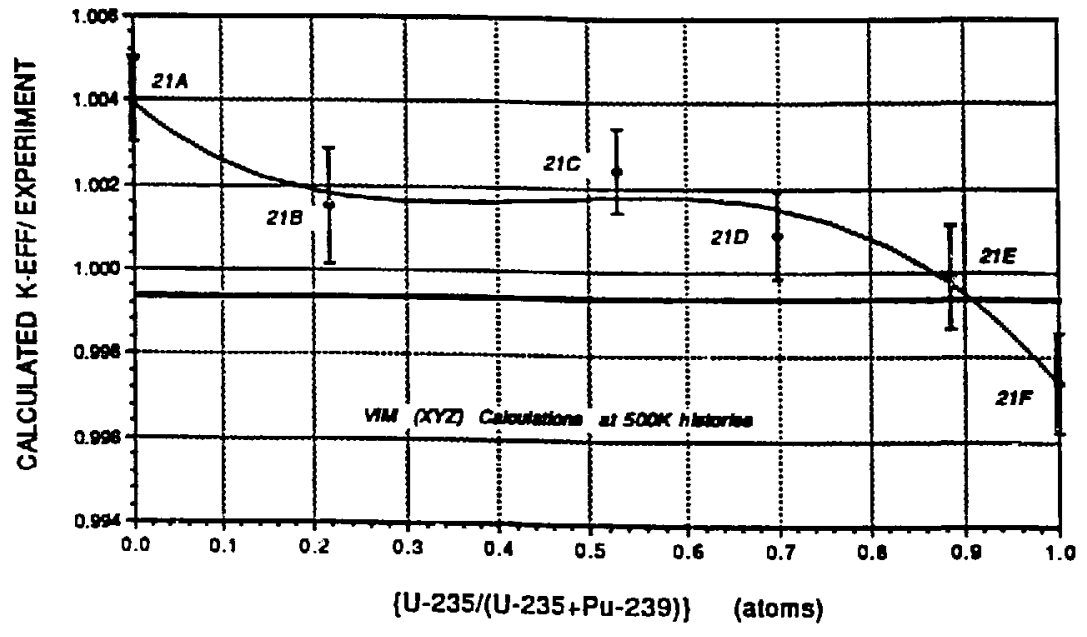

Figure 4 Ratio of Calculations to Experiment (ENDF/BV. 2 data) in ZPPR-21

\begin{tabular}{lcccc} 
Assembly & k-effective & $\begin{array}{c}\text { Standard } \\
\text { Deviation }\end{array}$ & $\frac{C / E}{0.048}$ & $\begin{array}{c}\text { Standard } \\
\text { Deviation }\end{array}$ \\
\cline { 2 - 2 } & 1.00467 & 0.0098 & 1.0044 & 0.0016 \\
ZPPR-21B & 1.00247 & 0.00136 & 1.0024 & 0.0018 \\
ZPPR-21C & 1.00101 & 0.00099 & 1.0017 & 0.0017 \\
ZPPR-21D & 1.00260 & 0.00104 & 1.0012 & 0.0019 \\
ZPPR-21E & 1.00069 & 0.00124 & 0.9998 & 0.0022 \\
ZPPR-21F & 0.99842 & 0.00118 & 0.9979 & 0.0024
\end{tabular}

Table III Results of Monte Carlo Calculations with the VIM Code and ENDF/B-V.2 Data 
and Pu benchmark cores, GODIVA and JEZEBEL, and for the IFR. Multigroup spectra for these cores are compared in Eigure 5 .

The results of fitting the ZPPR-

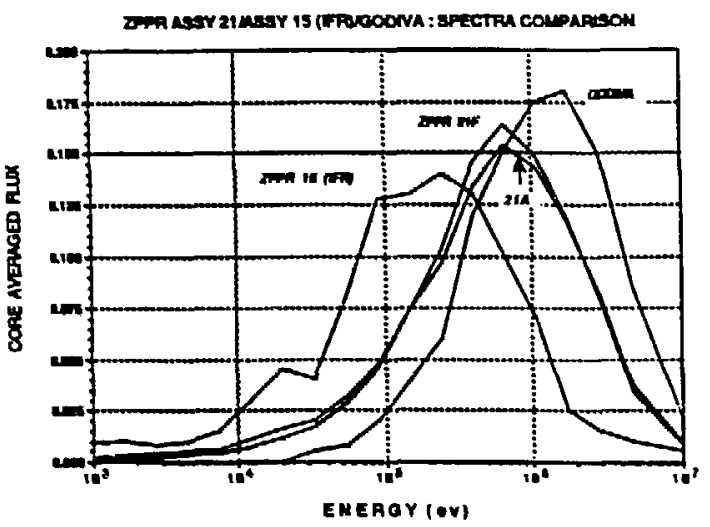

Figure 5 Spectra in GODIVA, ZPPR-21, and the IFR.

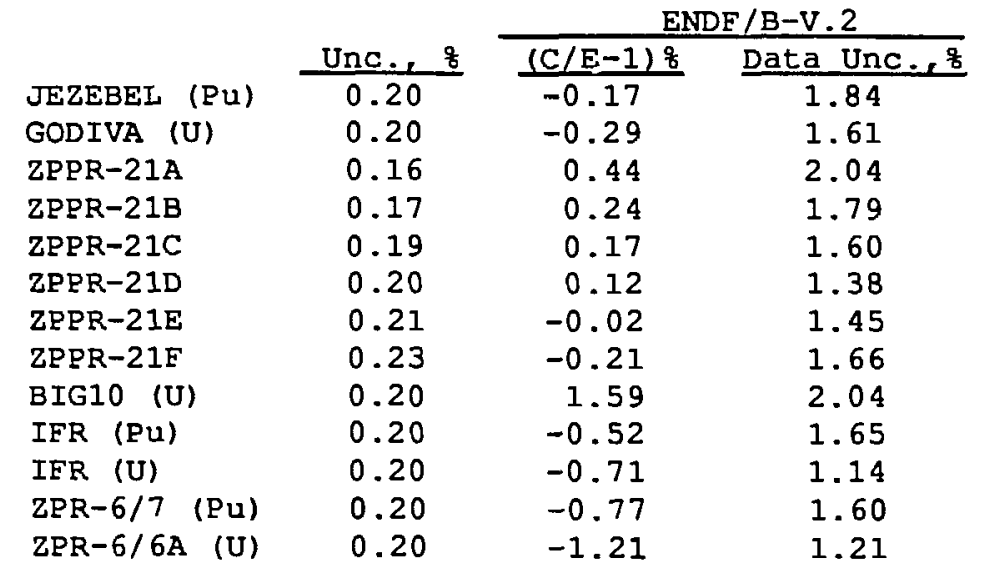

21 data are shown in Table IV. A small selection of other relevant results is included. BIGI0 is a uranium core of $10 \%$ enrichment built at LANL . 2PR-6/7 and 6/6A are plutonium and uranium oxide benchmark cores. Note that the whole database is used in the fit, including cores and parameters that are not shown in the table. Uncertainties in 2PPR-21 due to ENDF/B-V.2 data (column 4) range from 1.4 to $2.1 \%$ compared with uncertainties in measurement and calculation of $0.2 \%$. The data fitting (column 5) gives excellent results and uncertainties of $0.2 \%$ or less (column 6). These results show that the ZPPR21 data are consistent with independent measurements in JEZEBEL and GODIVA and with the IMR critical cores.

Table IV Results of IS Fitting of ZPPR-21 and other Selected Data

\section{AN RZ MODEL FOR ZPPR-21: CALCULATIONS WITH KENO}

The fully-detailed model of ZPPR-21 requires a vast amount of data and must be set up automatically as in the VIM calculations. A simple alternative is to use an $\mathrm{RZ}$ model using only a few regions with homogeneous compositions, as shown in Figure 2. Calculations with this model in the TWODANT code[6] were used to provide delayed neutron parameters for the data processing. Between the assemblies, the model differs in the core composition and reflector radius.

Geometric and heterogeneity corrections to the Rz model were generated by a second set of calculations with the VIM code and by comparison with results from the detailed model. These corrections were less than $0.75 \% \Delta k$ and were generated with a statistical uncertainty of $0.17 \% \Delta \mathrm{k}$ or better. 
The widely used and accepted code for criticality safety is KENO. [3] Calculations for 2PPR-21 in the Rz model have been made with KENO-5a. The results, together with VIM corrections to the model, are shown in Table V. The calculations were run for 104 generations with 5000 neutrons per generation. The first 4 generations were skipped to give the quoted k-eff with standard deviation of $0.18 \Delta K$ or better. Corrections to the Rz model are given in column 4 of the table with uncertainties in the correction factor in column 5. The ratio of corrected KENo results to experiment (C/E) are shown in column 6. The final uncertainties are the RMS of three independent values, for the experiment, the KENO statistics and the correction.

\begin{tabular}{|c|c|c|c|c|c|c|}
\hline & $\begin{array}{l}\text { Calc. } \\
\text { k-efi }\end{array}$ & $\begin{array}{c}\text { Std } \\
\text { Dev. } 8\end{array}$ & $\begin{array}{l}\text { R2 Model } \\
\text { Correction }\end{array}$ & $\begin{array}{c}\text { Std } \\
\text { Dev. } \frac{8}{8} \\
\end{array}$ & C/E & $\begin{array}{r}\text { Std } \\
\text { Dev. }\end{array}$ \\
\hline & $\overline{1.00314}$ & 0.109 & 1.00721 & 0.156 & $1 . \overline{0101}$ & 0.002 \\
\hline & 1.00632 & 0.102 & 1.00429 & 0.174 & 1.0105 & 0.00 \\
\hline & 1.01100 & 0.097 & 1.00597 & 0.153 & 1.0178 & 1. \\
\hline & 1.01240 & 0.102 & 1.00096 & 0.149 & 1.0120 & . \\
\hline $1 E$ & 1.01148 & 0.095 & 0.99607 & 0.167 & 1.0066 & \\
\hline & 44 & 89 & .99479 & 68 & .0006 & \\
\hline
\end{tabular}

Table $v$ Results of Calculations with the KENO-5a Code.

The KENO results show an overprediction of about 18 in the $\mathrm{Pu}$ loading of $21 \mathrm{~A}$ and a smaller error in the uranium fuel of $21 \mathrm{~F}$. Errors are larger in the mixed $P u / U$ fuel of $21 \mathrm{C}$ and $21 \mathrm{D}$. . Total uncertainties in these calculations are between 0.28 and $0.3 \%$. The increased error in the mixed $\mathrm{Pu} / \mathrm{U}$ fuel is not found in the VIM calculations of Table III. Since KENO is a multigroup code, calculations are not conceptually as complete as those from VIM. The uncertainties, of less than $0.38 \Delta k$, are adequate for most criticality safety calculations. More accurate values from KENO could be obtained by calculations with the fully-detailed model.

\section{A CALCULATION WITH THE MCNP CODE}

A calculation for 2PPR-21B in full detail has been made with the MCNP code [7] and ENDF/B-V data. The compositions and dimensions of the model were setup with a preliminary converter code which reads the VIM input. Like VIM, MCNP uses a continuous-energy desciption of the cross sections. Only 100-thousand histories were run since the combinational geometry processor was significantly more expensive than the special plate-lattice geometry option used with VIM. It is satisfying that the results were consistent within the statistics:

$\begin{array}{lllll}\text { MCNP } & 100 \mathrm{~K} \text { histories } & \text { K-eff } 1.00331, & 1 \sigma & 0.0024 \\ \text { VIM } & 490 \mathrm{~K} \text { histories } & \text { K-eff } 1.00247, & 1 \sigma & 0.00136\end{array}$

\section{SUMMARY}

The criticality of a series of $\mathrm{Pu} / \mathrm{U} / \mathrm{Zr}$ fuel mixtures of medium enrichment has been measured in ZPPR-21. A detailed sensitivity analysis has been used to show the consistency of the data with a wide range of fast reactor measurements. This gives strong confidence in the measured data.

Calculations, with ENDF/B-V.2 data, have been made using fully-detailed models, with the VIM continuous-energy Monte Carlo code. A simple Rz model of the experiments is defined with geometric correction factors generated to high accuracy by the VIM code. This model may be used with any other code 
and data provided that the cross sections are not sufficiently different to those of ENDF/B-V.2 to invalidate the treatment of heterogeneity.

The ZPPR-21 configurations are markedly more complex than the usual assemblies used for the basic validation of criticality codes and data. This 'deficiency' is made unimportant by availability of an automated processing code which creates the complex VIM input directly from the ZPPR loading database.

Calculations with the R' model and the kENO-Va code are of adequate accuracy to validate criticality safety calculations in the mixed fuel compositions. No previous data with this fuel type existed for this purpose. The ZPPR-2l data provide an essential part of the validation of calculations in fuel processing operations for the Integral Fast Reactor.

\section{ACKNOWLEDGEMENTS}

Assistance with running the experiments was provided by D. M. Smith, $R$. W. Goin and R. E. Kaiser. The reference calculations were made by G. I. Grasseschi and J.A. Steinhauer. KENO calculations were done by D. M. Smith. Sensitivity analysis was made by S. E. Aumeier. R, W. Schaefer gave essential assistance in using the ZPPR/VIM processing system and in the design of the experiments.

\section{REFERENCES}

[1] IFR Crucibie Operations, "Final Safety Analysis Report for the Fuel Cycle Facility," Chapter 6, in production 1991.

[2] R. N. BLOMOUIST, R. M. LELL and E. M. GELBARD, "VIM - A Continuous Energy Monte Carlo Code at ANL," A Review of the Theory and Application of Monte Carlo Methods, Proc. of a Seminar Workshop, Oak Ridge Tennessee, April 21-23, 1980, ORNL-RSIC-44, p 31, August 1980.

[3] L. M. PETRIE and N. F. LANDERS, "Keno V.a-An Improved Monte Carlo Criticality Program with Supergrouping," Oak Ridge National Laboratory Report NUREG/CR-0200, Volume 2, Section F11, ORNL/NUREG/CSD-2/VI/R2 (December 1984).

[4] R. D. MCKNIGHT, P. J. COLLINS and D. N. OLSEN, "The Critical Eigenvalue in LMFBRs: A Physics Assessment," Proc. Topical Meeting on Reactor Physics and Shielding, Sept. 17-19, Chicago, IL, 1984, p 750 .

[5] W. P. Poenitz and P. J. Collins, "Utilization of Experimental Integral Data of the Adjustment and Uncertainty Evaluation of Reactor Design Quantities," Proc. Specialists Meeting on Application of́ Critical Experiments and Operating Data to Core Design Versus? Formal Methods of Cross Section Data Adjustment, Jackson Hole, Wyoming, Sept. 23-24, 1988 .

[6] R. E. ALCOUFFE et al., "Users Guide for TWODANT: A Code Package for Two-Dimensional, Diffusion Accelerated, Neutral Particle, Transport, " Los Alamos National Laboratory Report, LA-1000490M, March 1984 and Revisions.

[7] J. F. BRIESMEISTER, "MCNP - A General Monte Carlo Code for Neutral and Photon Transport'" Los Alamos Natiorial Laboratory Report, LA-7396-M, Rev. 2, Updated 1988. 